\title{
Frequency Distribution Analysis of a Maize Population as a Tool in Maize Breeding
}

\author{
V. GREVENIOTIS ${ }^{1 *}$, E. SIOKI ${ }^{2}$ and C.G. IPSILANDIS ${ }^{3}$ \\ ${ }^{1}$ Department of Agricultural Development, Democritus University of Thrace, Orestiada, 68200, Greece \\ ${ }^{2}$ Hellenic Agricultural Organization - "Demeter", National Center For Quality Control, \\ Classification \& Standardization of Cotton, $1^{\text {st }} \mathrm{km}$ Karditsa-Mitropolis, 43100, Karditsa, Greece \\ ${ }^{3}$ Regional Administration of Central Macedonia, \\ Department of Agriculture, 63, A. Papanastasiou str., Thessaloniki 54453, Greece
}

(Received 16 January 2017; Accepted 24 May 2017;

Communicated by T. Harangozó)

\begin{abstract}
The objective of this study was to investigate the distribution of progressive selection generations in order to define the maximum efficiency of increasing yield in relation to the stage of selection procedure. Experimental procedure lasted five years on open-pollinated lines selected in two contrasting environments under low plant population. Mean grain yield of individual maize plants increased by $79 \%$ from $\mathrm{C} 0$ to $\mathrm{C} 4$ generation in environment $\mathrm{A}$ and $32 \%$ in environment $\mathrm{B}$. Yield of individual plants was increased by $58 \%$ from $\mathrm{C} 0$ to $\mathrm{C} 2$ when selection was fully practiced in environment $\mathrm{B}$. The progressive reduction of $\mathrm{CV}$ values through the selection generations revealed gene fixation and lack of segregation in selected lines which tended to be more uniform and homozygous. Low to medium negative kurtosis and low to medium positive skewness, accompanied by a more "squared" shape of distribution curve may indicate more homozygous genetic material that was categorized in clusters of similar $\mathrm{C} 4$ lines as was observed in environment $\mathrm{A}$, depicting the end of selection procedure. In $\mathrm{C} 4$, a breeder may choose from the upper part of distribution curve (higher yielding plants) in order to avoid possible selection of deleterious genes at the kurtosis-biased lower part of the distribution curve. Our findings suggested the selection of cultivars of narrow adaptation, because at the initial stages of the selection program the effect of environment lead to different genetic materials, favouring certain genotypes. In our study environment B favoured selection procedure for developing high yielding open-pollinated lines for breeding and farming purposes.
\end{abstract}

Keywords: selection efficiency, skewness, kurtosis, deviation, clusters

\section{Introduction}

Maize (Zea mays L.) is one of the most important crops worldwide, as it provides feed, food, and fuel (Hefny 2010). Fischer and Edmeades (2010) reported that relative rates of yield increase are declining and estimated the relative rate of yield increase at about $1.5 \%$ $\mathrm{yr}^{-1}$. In order to overcome the stagnation in the gains in grain yield from maize breeding 
due to the large number of deleterious genes, different selection and breeding approaches have been adopted (Hallauer and Miranda 1981; Fasoulas 1988, 1993). Ipsilandis and Koutsika-Sotiriou (2000) and Ipsilandis et al. (2006), showed the importance of improving maize inbred line performance per se, by selecting for favorable additive gene action. They reported improved yielding performance not only for parental lines but also for crosses between these lines. The genetic improvement of single-cross hybrids has been associated primarily with increased tolerance to various biotic and abiotic stresses (Duvick 2005). This is also in relation to the genotype by environment interaction, a bidirectional phenomenon that distorts genotype behaviour in the environment that it is cultivated (Constantinidou and Fasoulas 1988). Romagosa and Fox (1993) described the genotype ranking changes in relation to the environment and Fasoulas $(1988,1993)$ concluded that a commercial cultivar must be independent of the local environment using inter-location selection.

Falconer (1960) described the theoretical distributions of genes. Moreover, Fasoulas (1988) analysed the theoretical distributions of genes in an effort to define efficiency in breeding. He stated that narrow spacing through evaluation procedure narrows and distorts distribution of open pollinated populations. Fixation of deleterious genes may also distort distribution exhibiting positive skewness (Fasoulas 1988). Maize breeding programs depend on an excessive exploitation of heterosis, exhibited mainly by alleles showing dominance and sometimes overdominance effects (Falconer 1960). According to Kearsey and Pooni (1992), heterosis is caused by dispersed genes showing mainly directional dominance and Fasoulas (1993) believes that heterosis is the effect of masking deleterious alleles by favourable alleles in heterozygous loci. Additive gene action is of great importance because it insures heritable and stable performance, although it is accompanied by inbreeding depression (Fasoulas 1993; Ipsilandis and Koutsika-Sotiriou 2000). Inbreeding depression is the fixation of deleterious genes in S1 maize progenies and distribution in these cases shows negative kurtosis in comparison to Half-sib progenies (Ipsilandis et al. 2005). For $\mathrm{F}_{2}$ generation and S1 progenies' distributions, departure from normality found many times present, indicating deleterious gene action, while positive skewness, indicates the presence of inferior genotypes exhibiting inbreeding depression, which is absent in half-sib (HS) yield distribution (Fasoulas 1993; Ipsilandis et al. 2005).

With respect to maize, an out-crossing crop, selection increased mean yield, and yield distributions even though tended to be normal in the advanced selection cycles, they showed significant negative kurtosis and positive skewness (Gogas 1987). Negative kurtosis and positive skewness could also be present when evaluating genotypes in dense stand (Kyriakou and Fasoulas 1985), where competition is reduced and distorts yield distribution (Fasoulas 1988). In general, selection procedure configures yield distribution, which tends to be normal in advanced selection cycles and the mean of the new improved populations is higher and shifted to the right (Hallauer and Miranda 1981).

The objective of this study was to investigate the distribution of progressive selection generations in order to define the maximum efficiency of increasing yield in relation to the stage of selection procedure. 


\section{Materials and Methods}

The genetic materials used in this study were the $\mathrm{F}_{2}$ generation $(\mathrm{C} 0)$ of the commercial maize hybrid Costanza (Pioneer HiBred Int.), produced in an isolated field under open pollination (random mating). The experiments were performed in two contrasting environments, environment A (Florina, 40 46’ $\mathrm{N}, 21^{\circ} 22^{\prime} \mathrm{E}$, altitude $705 \mathrm{~m}$ ) and environment $\mathrm{B}$ (Trikala, $39^{\circ} 55^{\prime} \mathrm{N}, 21^{\circ} 64^{\prime} \mathrm{E}$, altitude $120 \mathrm{~m}$ ). Nitrogen and P fertilizer were applied at the rate of 150 and $75 \mathrm{~kg} \mathrm{ha}^{-1}$, respectively, at sowing, while additional $\mathrm{N}\left(135 \mathrm{~kg} \mathrm{ha}^{-1}\right)$ was applied when the plants reached $50 \mathrm{~cm}$ in height. Weed control was obtained by tilling and manual hoeing. Evaluation and selection of individual plants were performed under ultra-wide plant spacing because competition interferes with the equal sharing of growth resources (Fasoulas 1993). All trials were regularly irrigated after planting to avoid drought stress.

\section{Basics of methodology}

Selection of individual plants was based on honeycomb methodology (Fasoulas 1988; Fasoula 2013). In initial populations non-replicated honeycomb designs (NR-0) were used (Fig. S1*), as described by Fasoulas (1988). In half-sib progenies replicated designs were used as the R-7 presented in Fig. S2 (Fasoulas 1988). In all experiments, the plantto-plant spacing was $1.25 \mathrm{~m}$ (wide-spaced, Fasoulas 1988) and plants were grown in isolation and under open pollination. Three seeds were planted per hill and plants thinned to one plant per hill four weeks later (after planting). In non-replicated designs, superior plants and lines were selected using the plant yielding index PYI $=\left(x / \bar{x}_{r}\right)^{2}$ proposed by Fasoula $(2006,2013)$. In replicated designs, superior plants and lines were selected on the basis of the two selection equations, the plant prognostic equation $\left(x / \bar{x}_{r}\right)^{2} \cdot(\bar{x} / s)^{2}$ and the line prognostic equation $\left(\bar{x} / \bar{x}_{t}\right)^{2} \cdot(\bar{x} / s)^{2}$, where $x$ is the yield per plant, $\bar{x}_{r}$ is the mean plant yield of the surrounding plants within the moving ring, $\bar{x}_{t}$ is the overall mean plant yield of the experiment, $\bar{x}$ and $s$ are the entry (family) mean yield and standard deviation (Fasoula 2006, 2013). At the appropriate timing (before pollen sheds), the tassels of Costanza plants were covered with bags to avoid dispersal of $F_{1}$ and $F_{2}$ pollen that could potentially bias results.

\section{Experiments in 2007}

The study was initiated in 2007 with $2,349 \mathrm{~F}_{2}(\mathrm{C} 0)$ plants of the $\mathrm{F}_{1}$ commercial hybrid Costanza in environment A (Greveniotis 2012). The trial was established on 4 May 2007 using the non-replicated honeycomb design NR-0 (Fasoulas 1988) with the plants grown under open pollination. The plants were harvested individually on 7 and 9 November 2007. Using the formula PYI $=\left(x / \bar{x}_{r}\right)^{2}$ proposed by Fasoula $(2006,2013)$ the 29 top highyielding plants were selected for the subsequent cycles of selection. Despite the use of

*Further details about the Electronic Supplementary Material (ESM) can be found at the end of the article. 
open-pollination, the pedigree selection scheme was conducted for all years of experimentation on the half-sib progenies.

\section{Experiments in 2008}

In 2008, the 29 selected plants along with the $\mathrm{F}_{2}$ and the $\mathrm{F}_{1}$ commercial hybrid check Costanza were evaluated using a replicated honeycomb design (R-31) (Fasoulas 1988) in both contrasting environments $\mathrm{A}$ and $\mathrm{B}$. There were 31 entries with 50 plants per entry. In parallel in additional experiments, the 11 best among 29 selected $\mathrm{C} 1$ plants plus the $\mathrm{F}_{2}$ and the $\mathrm{F}_{1}$ commercial hybrid checks Costanza were evaluated using a replicated honeycomb design (R-13) in both environments. Experiments were established on 9 May 2008 and on 4 May 2008 in environments A and B, respectively. Experiments were harvested on 10 December 2008 in environment A and on 17 October 2008 in environment B. Selection was based on the values of prognostic equations (Fasoula 2006, 2013) and the top 19 plants were selected in each environment.

\section{Experiments in 2009}

In 2009, the $19 \mathrm{C} 2$ selected plants from 2008 along with the $F_{2}$ and the $F_{1}$ commercial hybrid Costanza were grown using the replicated R-21 honeycomb design (Fasoulas 1988 ) in both environments A and B. There were a total of 21 entries with 70 plants per entry in each environment. Experiment in environment A was established on 10 May 2009 and in environment B was established on 6 April 2009. Experiments were harvested on 29 November 2009 in environment A and on 10 October 2009 in environment B. Five top plants were selected from each of the best two $\mathrm{C} 2$ lines in environment A (10 plants in total) and five plants from the best sibling $\mathrm{C} 2$ line in environment $\mathrm{B}$, corresponding to the ultra-high selection pressure of $0.4-0.7 \%$. Superior plants in environments A and B were selected based on the values of prognostic equations, because of the efficiency of honeycomb selection in high selection pressures (Fasoula 2006, 2013).

\section{Experiments in 2010}

In 2010, selected C3 plants were evaluated in three R-7 replicated honeycomb designs (Fasoulas 1988). In environment A, two separate replicated R-7 designs were established to evaluate the previously selected $10 \mathrm{C} 3$ plants in environment $\mathrm{A}$, developed from the two $\mathrm{C} 2$ selected lines along with $\mathrm{F}_{1}$ Costanza and also the two $\mathrm{C} 2$ line as checks. In environment $\mathrm{B}$, one replicated R-7 trial was established to evaluate the best 5 plants for the selected line along with Costanza and the $\mathrm{C} 2$ line. There were 100 individual plant replications for each entry. The trials in environment A were established on 6 May 2010 and the trial in environment B was established on 8 April 2010. Trials were harvested on 18 December 2010 in environment A and on 20 October 2010 in environment B. The 12 top-yielding plants were selected from each experiment in environment A (24 in total) and 12 top plants from environment B, based on the values of prognostic equations (Fasoula 2006, 2013). 
Experiments in 2011

In 2011, the $12 \mathrm{C} 4$ top plants selected from each C3 experiment in environment A along with the $\mathrm{F}_{1}$ hybrid Costanza, were grown in two separated replicated R-13 honeycomb designs (Fasoulas 1988) in environment A. Similarly, the 12 C4 top plants selected from $\mathrm{C} 3$ in environment $\mathrm{B}$ along with $\mathrm{F}_{1}$ Costanza, were also evaluated in a replicated $\mathrm{R}-13$ design in environment $\mathrm{B}$. There were 75 individual plant replications for each entry. Trials were established on 7 April 2011 in environment A and on 15 May 2011 in environment $\mathrm{B}$, and harvested on 16 December 2011 in environment $\mathrm{A}$ and on 1 October 2011 in environment $\mathrm{B}$.

\section{Experiments in 2009-11 (in environment B)}

This study was first initiated from the $\mathrm{F}_{2}(\mathrm{C} 0)$ of Costanza in environment $\mathrm{A}$ as described before. Because selected data in previous years indicated a strong $\mathrm{G} \times \mathrm{E}$ interaction between the two diverse environments, a new selection cycle started in 2009 in environment $\mathrm{B}$ in the $\mathrm{F}_{2}(\mathrm{C} 0)$ generation of the $\mathrm{F}_{1}$ hybrid Costanza, in order to estimate accurately the genetic gain in this specific environment in contrast to environment $\mathrm{A}$ and in comparison to experiments established in environment B but their starting material was originated from environment A (Greveniotis 2012). In this experiment $1380 \mathrm{~F}_{2}$ plants of commercial maize hybrid Costanza were evaluated using a non-replicated NR-0 honeycomb design (Fasoulas 1988). It was established on 6 April 2009 and the plants were harvested on 10 October 2009. Selection was based on the PYI (Fasoula 2006, 2013) and the 29 top plants were selected.

In 2010, the $29 \mathrm{C} 1$ lines, along with the $\mathrm{F}_{2}$ and $\mathrm{F}_{1}$ Costanza, were grown in a replicated R-31 honeycomb design in environment $\mathrm{B}$. This experiment evaluated 31 entries with 70 plants per entry. The experiment was established on 8 April 2010 and harvested on 20 October 2010. Selection was based on the prognostic equations to identify the top 19 plants (Fasoula 2006, 2013).

In 2011, the $19 \mathrm{C} 2$ lines, along with the $\mathrm{F}_{2}$ and the $\mathrm{F}_{1}$ hybrid Costanza, were grown in a replicated R-21 honeycomb design in environment B. This experiment evaluated 21 entries with 60 plants per entry. It was established on 7 April 2011 and harvested 1 October 2011. Selection was based on the prognostic equations (Fasoula 2006, 2013) to identify the top 29 plants for future evaluation.

\section{Statistical analysis}

Distributions of individual plants' yield were plotted for all years of experimentation (limits have been set the same for all plots, for better comparison). Also, coefficient of variation $(\mathrm{CV} \%)$, means, skewness and kurtosis were computed. Q-Q plots were used to study departure from normal distribution. SPSS ver. 17 was used for statistical analysis. 


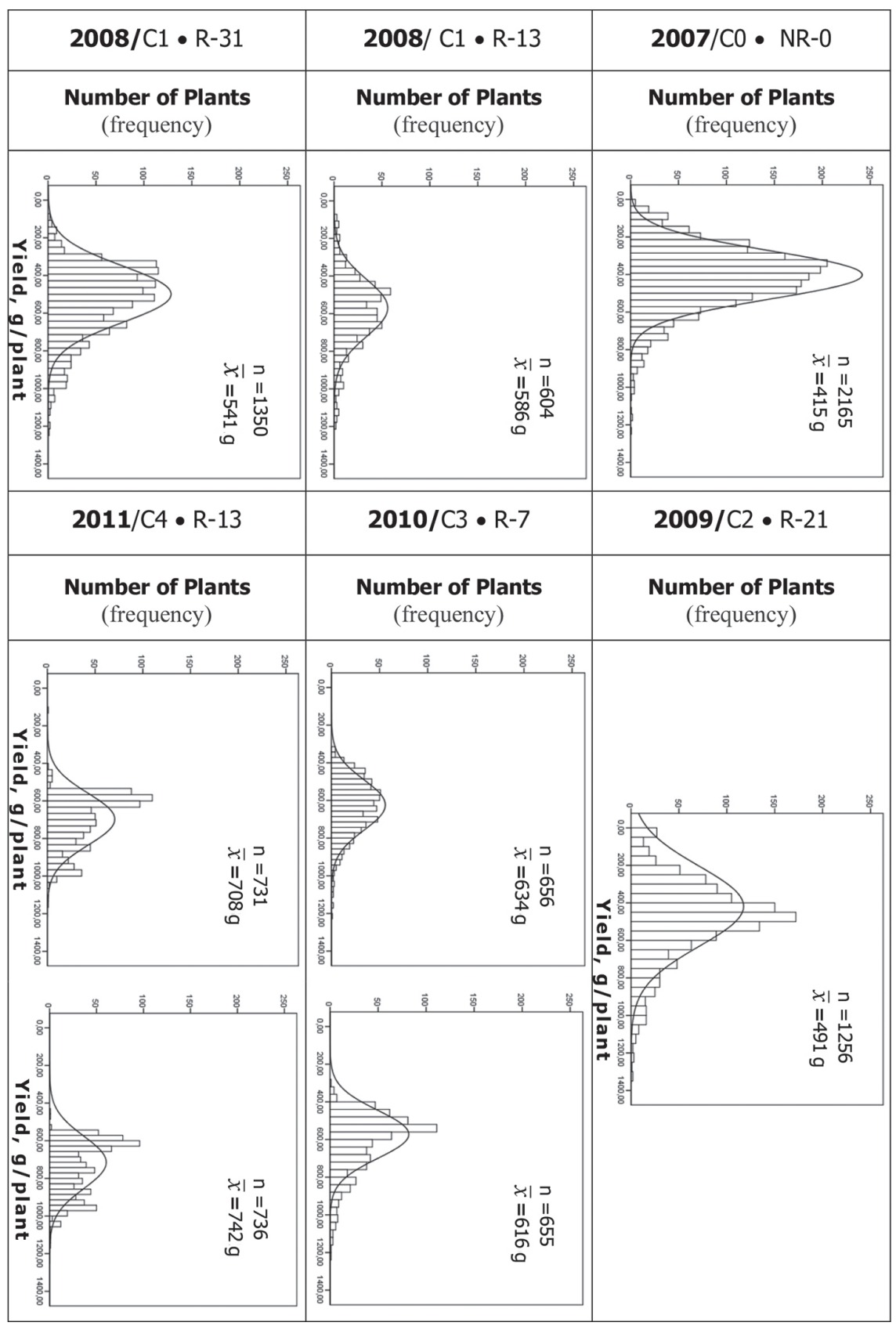

Figure 1. Yield distributions of individual maize plants under wide spacing of progressive generations $(\mathrm{C} 0-\mathrm{C} 4)$ in environment $\mathrm{A}$, starting material in environment $\mathrm{A}$ (where $\bar{x}$ is the total mean of individual plants and $\mathrm{n}$ is the total number of plants) 


\section{Results}

Our data set showed that the mean yield of individual plants of maize was increased from $415 \mathrm{~g}$ in $\mathrm{C} 0$, to 708 and $742 \mathrm{~g}$ in C4 in environment A and to $547 \mathrm{~g}$ in C4 in environment $\mathrm{B}$ (Table S1). Furthermore, the yield of individual plants increased from $311 \mathrm{~g}$ in $\mathrm{C} 0$ to $492 \mathrm{~g}$ in $\mathrm{C} 2$ when selection was fully practiced from $\mathrm{C} 0$ in the environment $\mathrm{B}$. The progress in Florina (environment A) was faster than in Trikala (environment B), since mean yield increased (from $\mathrm{C} 0$ ) by 71 and $79 \%$ in $\mathrm{C} 4$ in environment $\mathrm{A}$ and only by $32 \%$ in environment $\mathrm{B}$, keeping in mind that, this starting material was established in Florina and selection started there. When selection started from $\mathrm{C} 0$ in Trikala, mean yield increased by $58 \%$ (in comparison to $\mathrm{C} 0$ ) already from $\mathrm{C} 2$ selection generation. Mean yield of 743 $\mathrm{g}$ in environment $\mathrm{A}$ was the maximum and $708 \mathrm{~g}$ also found in the second experiment of environment $\mathrm{A}$, followed. In environment B means were lower and progress was slower. $\mathrm{C} 1-\mathrm{C} 4$ progress found in environment $\mathrm{A}$ was $37 \%$ and in environment $\mathrm{B}$ (starting material in A) was $27 \%$, indicating also a faster progress in Florina (Table S1).

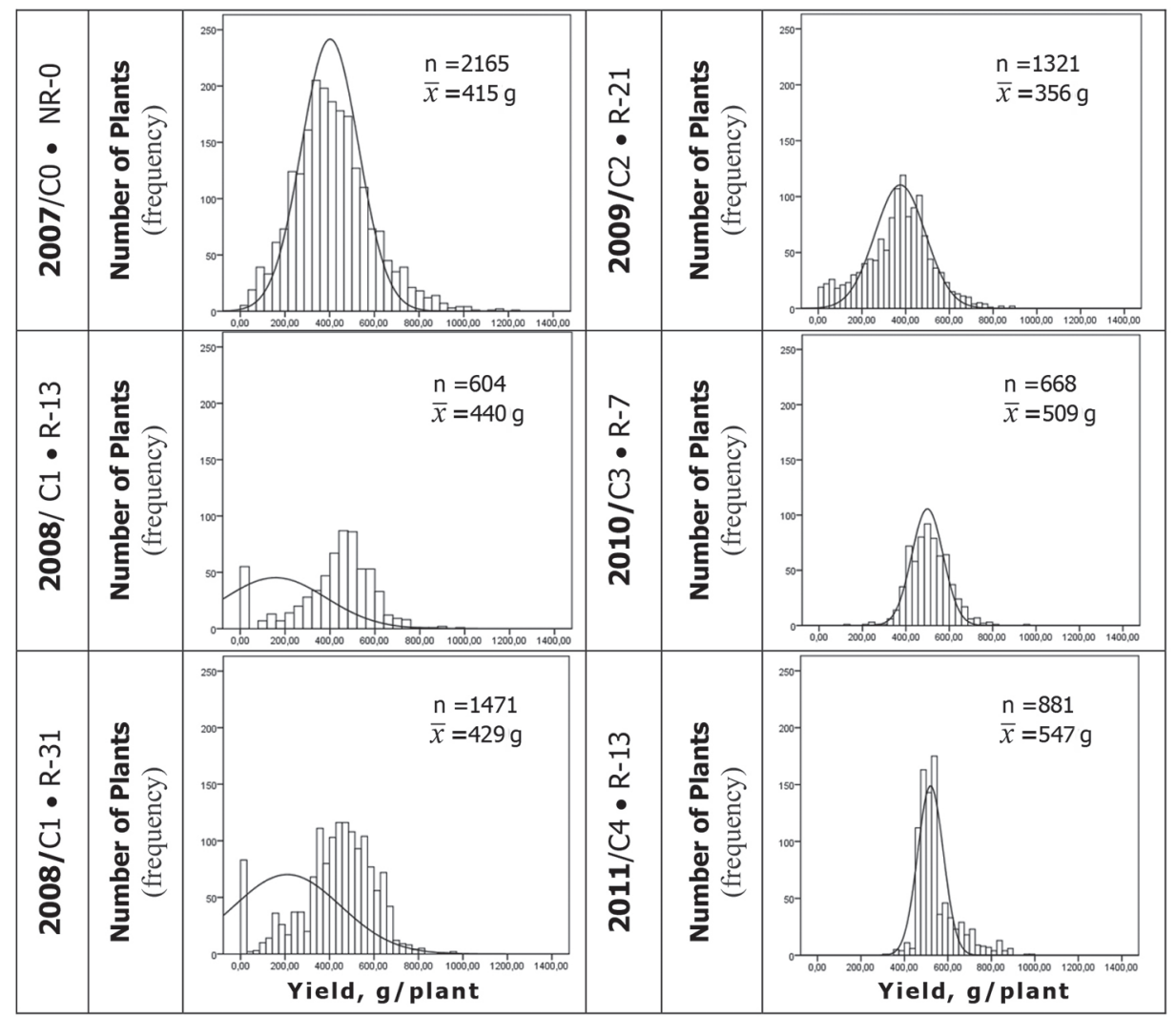

Figure 2. Yield distributions of individual maize plants under wide spacing of progressive generations $(\mathrm{C} 0-\mathrm{C} 4)$ in environment $\mathrm{B}$, starting material in environment $\mathrm{A}$ (where $\bar{x}$ is the total mean of individual plants and $\mathrm{n}$ is the total number of plants) 


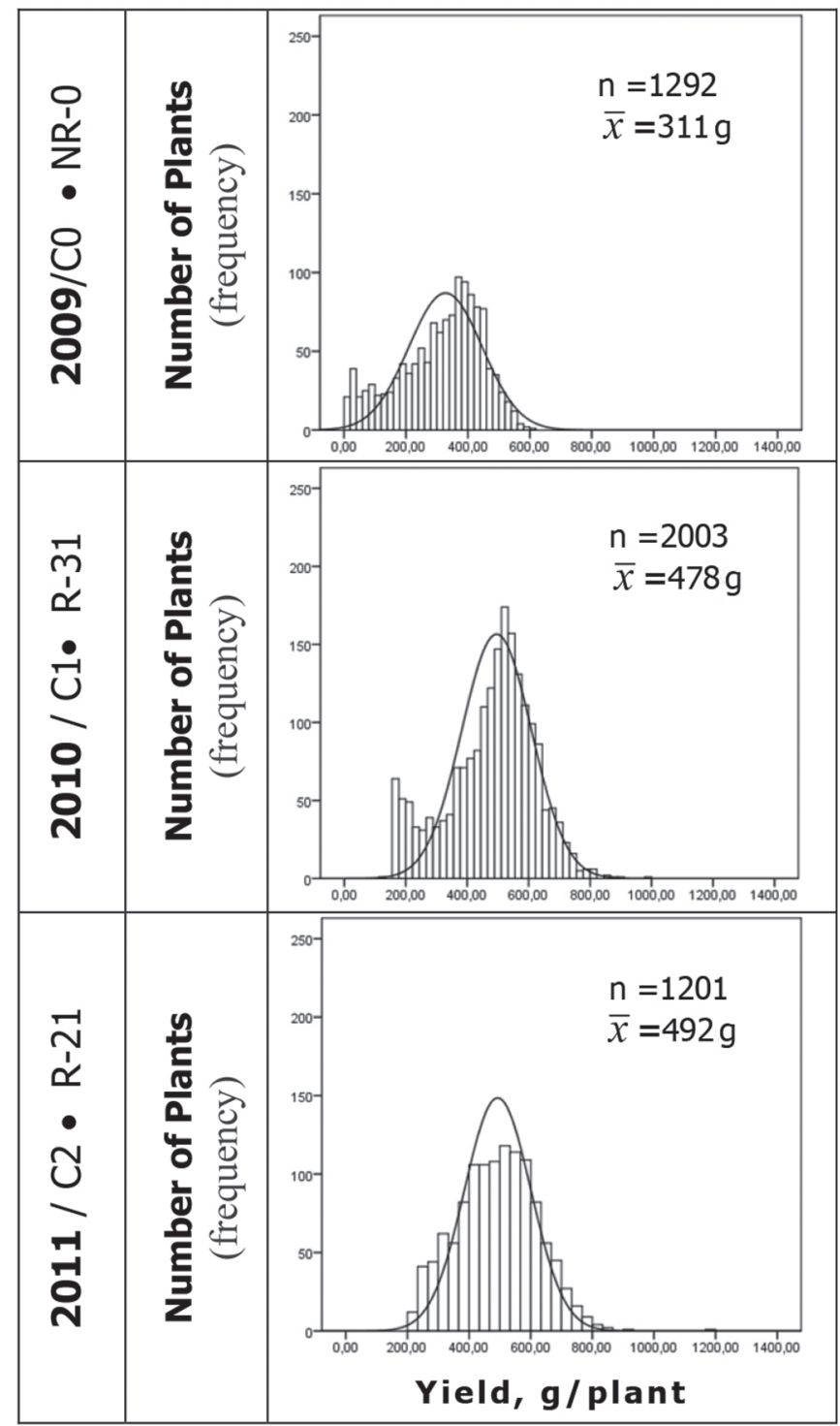

Figure 3. Yield distributions of individual maize plants under wide spacing of progressive generations $(\mathrm{C} 0-\mathrm{C} 2)$ in environment $\mathrm{B}$, starting material in environment $\mathrm{B}$ (where $\bar{x}$ is the total mean of individual plants and $\mathrm{n}$ is the total number of plants) 
Coefficient of variation (CV\%) in environment A decreased at 19-20\% in C4 and in environment $\mathrm{B}$ at $17 \%$ from $42 \%$ in $\mathrm{C} 0$, while in $\mathrm{C} 2$, when selection started from $\mathrm{C} 0$ in Trikala, it decreased at $26 \%$ from $43 \%$ in $\mathrm{C} 0$. The shape of the curves changed throughout the breeding process in both the selection environments.

In environment $\mathrm{A}$, most of the individuals' yield distributions showed an upper limit near to 1200 to $1400 \mathrm{~g}$. In environment B there were many changes in the upper limit of distribution showing a kind of retrogression, without a clear initial progress of top yielding plants (Figs 1, 2 and 3).

In Trikala, skewness and kurtosis were very low when selection started from $\mathrm{C} 0$ in this environment ( 0.2 and 0.1 , respectively, in $\mathrm{C} 2)$, but it was found different when selection started from $\mathrm{C} 0$ in environment A and drift from normality was apparent. Skewness and kurtosis are estimations of curves' departure from normal distribution, by inflating and narrowing the real distribution of individual data. Fasoulas (1988) considered that this is an indication of the presence of unfavourable genes that a breeder has to remove during the selection procedure. In Florina, negative kurtosis was present in the last generations (Table S1). Better presentation is evident in distribution plots of experiments in environments A and B (Figs 1, 2 and 3). In environment A, curves were distorted after the first year showing progressively a more "square" shape and a classification of plants in distinct groups. The total number of classes tended to be progressively lower. In environment B, this was not so clear. When selection started in environment B, the curve tended to be normal.

\section{Discussion}

According to Fasoulas (1988), distributions and the respective statistics, may reveal the gene composition of a certain population, especially the load of deleterious genes that are unmasked in segregating genetic materials of cross-pollinated populations. Also, the progress of generations may define selection efficiency stage of the certain selection schemes that is finally reflected in the plot of distribution. The progress in Florina (environment A) was faster than in Trikala (environment B) indicating that environmental effects may influence the progress of selection. Local conditions of Florina favoured better plant response to selection, due to the honeycomb schemes used that select for specific adaptability, i.e. plants of narrow adaptation (Fasoulas 1988; Fasoula 2013). The progressive reduction of $\mathrm{CV}$ values through the selection generations reveals gene fixation and lack of segregation in selected lines which tend to be more uniform and homozygous (Fasoulas 1988; Greveniotis and Fasoula 2016). Furthermore, this may lead to low plant-to-plant competition, elimination of deleterious genes and stand uniformity (Fasoula 2013).

Departure from normality is usually present in progressive generations (Moll et al. 1977). In $\mathrm{F}_{2}(\mathrm{C} 0)$ a normal distribution is expected, especially for a large population (Hallauer and Miranda 1981). Fasoulas (1988) depicted that expected normal distribution of $\mathrm{F}_{2}$ population is depended on the load of deleterious genes that could distort normal distribution as indicated by significant negative kurtosis (Gogas 1987). Q-Q plots revealed departure from normality in many cases for our distributions. The $\mathrm{F}_{2}(\mathrm{C} 0)$ was almost 
normal in environment A, but in environment B there was an apparent deviation from normality. Generally, the distribution of the intermediate generations showed a departure from normality because of extensive gene fixation (Gogas 1987). In the C3, the distribution curve tended to be normal (in $\mathrm{C} 2$ in environment $\mathrm{B}$ when $\mathrm{C} 0$ started there), probably because variation increased through selection and sib-mating favouring increases in additive gene action and eliminating a number of deleterious genes. Later, in C4 a kind of classification (distinct classes) was present leading to a clear departure from normality indicating certain genotype selection that leads to classification of genotypes. The value of deviation depends on the gene frequencies in the population under discussion and help to clarify the effect of the interaction deviations. The value of deviation therefore depends on the population in which it is measured (Falconer 1960). Greveniotis et al. (2012) depicted the importance of incorporating favourable additive action as also reported by Crow (2000) and Troyer and Wellin (2009) and this is in agreement to our indications, in order to ensure efficiency in breeding.

In our data set, small to medium negative or low kurtosis and low to medium positive skewness was accompanied by a more "squared" shape of distribution curve (flat plot) and this may indicate a more homozygous genetic material that is categorized in certain clusters of similar lines according to their performance (Greveniotis 2012). This was more apparent in environment A, in C4 generation, where individual plants seemed to be categorized into 4-5 main clusters and may signal the end of the selection procedure. Under low plant density, in C4 the mean increased significantly and a breeder may choose from the upper part of the distribution curve in order to avoid possible selection of deleterious genes that may still be present at the kurtosis-biased lower part of distribution curve (Fasoulas 1988). In environment B with starting material derived from selection procedure in environment $\mathrm{A}$, this was not apparent and strong positive kurtosis and skewness was present. When selection started in environment $\mathrm{B}$, distribution tended to be almost normal, with increased mean. Clusters were not apparent in $\mathrm{C} 2$, indicating that selection could be continued. In case of favourable additive alleles accumulation, selection will be more secure and may result in high yielding inbred lines per se, as the final products of a successful breeding program in maize (Ipsilandis and Koutsika-Sotiriou 2000). In such cases, benefits for breeders and farmers will be great due to the exploitation of inbreeding superiority (Ipsilandis and Koutsika-Sotiriou 2000). Fasoulas (1988) depicted the importance of additive gene effects, instead of dominant or masking side effects of deleterious genes under heterozygosity, because they are heritable and improve distribution characteristics leading to a more normal curve.

From our data set, it is obvious that the initial selection site may influence positively the yield performance of the subsequent generations, resulting in better progress in case of Florina (environment A) and additionally, the same was found when selection started from $\mathrm{C} 0$ in Trikala (environment B). The genotype by environment interaction (GEI) is always present (Bernardo 2002) and a breeder must always keep in mind this parameter when establishing a new breeding program. GEI also defines the breeding procedure to be employed in a breeding program in order to select for cultivars of broad or narrow adaptation (Fasoulas 1988). Bernardo (2002) described the three ways of breeding procedure for 
eliminating or exploiting GEI. Our findings in the two environments suggest the selection of cultivars of narrow adaptation without inter-location selection, because starting environment used may lead to different kind of genetic materials. Starting environment favours certain genotypes and may boost the breeding procedure through selection of favourable additive gene action (Gogas 1987). Year interactions had a limited positive effect in comparison to the selection methods used and the starting environment's effects, since a continuous improvement throughout the breeding procedure was always present.

In our study, environment B seems to favour better selection procedure. Increasing number of favourable alleles may result in isolation of superior open-pollinated lines for breeding or farming purposes (Hallauer and Miranda 1981; Fasoulas 1988; Greveniotis and Fasoula 2016).

\section{Acknowledgements}

This research work was based on the remarks and support of professors A.C. Fasoulas, St. Zotis $^{+}$and C.K. Goulas. This research has been partly co-financed by the European Union (European Social Fund - ESF) and Greek national funds through the Operational Program "Education and Lifelong Learning" of the National Strategic Reference Framework (NSRF) - Research Funding Program: Heracleitus II. Investing in Knowledge Society through the European Social Fund.

\section{References}

Bernardo, R. 2002. Breeding for Quantitative Traits in Plants. Stemma Press. Woodbury, MN, USA. pp. 1-369. Constantinidou, K., Fasoulas, A.C. 1988. Evidence for the genetic basis of heterosis during hybrid reconstruction in maize. Proc. 2nd Congress of the Hellenic Soc. for the Genetic Improvement of Plants. Thessaloniki, Greece. pp. 215-225.

Crow, J.F. 2000. The rise and the fall of overdominance. Plant Breed. Rev. 17:225-257.

Duvick, D.N. 2005. Genetic progress in yield of United States maize (Zea mays L.). Maydica 50:193-202.

Falconer, D.S. 1960. Introduction to Quantitative Genetics. 1st ed. Oliver and Boyd. London, UK. pp. 1-365.

Fasoula, V.A. 2006. A novel equation paves the way for an everlasting revolution with cultivars characterized by high and stable crop yield and quality. Proc. 11th Congress of the Hellenic Society for the Genetic Improvement of Plants. Orestiada, Greece. pp. 7-14.

Fasoula, V.A. 2013. Prognostic breeding: A new paradigm for crop improvement. Plant Breed. Rev. 37:297347.

Fasoulas, A.C. 1988. The Honeycomb Methodology of Plant Breeding. A. Altidjis Publ. Thessaloniki, Greece. pp. $1-168$.

Fasoulas, A.C. 1993. Principles of crop breeding. A.C. Fasoulas, P.O. Box 19555, Thessaloniki, Greece. pp. $1-128$.

Fischer, R.A., Edmeades, G.O. 2010. Breeding and cereal yield progress. Crop Sci. 50:S85-S98.

Gogas, D.M. 1987. Controlled mass honeycomb selection for yield in segregating generations of single maize hybrid. Ph.D. Thesis, Dept. Genetics and Plant Breeding. Aristotle University of Thessaloniki. Greece. pp. $1-141$.

Greveniotis, V. 2012. Investigation of the possibilities to replace maize hybrids with open pollinated lines. Ph.D. Thesis, Dept. of Agricultural Development, Democritus University of Thrace. Orestiada, Greece. pp. $1-193$. 
Greveniotis, V., Fasoula, V.A., Papadopoulos, I.I., Sinapidou, E., Tokatlidis, I.S. 2012. The development of highly-performing open-pollinated maize lines via single-plant selection in the absence of competition. Aust. J. Crop Sci. 6:1448-1454.

Greveniotis, V., Fasoula, V.A. 2016. Application of prognostic breeding in maize. Crop Pasture Sci. 67:605620.

Hallauer, A.R., Miranda, F.J.B. 1981. Quantitative Genetics in Maize Breeding. 1st Ed. Iowa State Univ. Press. Ames, IA, USA. pp. 1-468.

Hefny, M. 2010. Genetic control of flowering traits, yield and its components in maize (Zea mays L.) at different sowing days. Asian J. Plant Sci. 2:236-249.

Ipsilandis, C.G., Koutsika-Sotiriou, M. 2000. The combining ability of recombinant S-lines developed from $\mathrm{F}_{2}$ maize population. J. Agric. Sci. Cambridge 134:191-198.

Ipsilandis C.G., Deligeorgidis, P.N., Giakalis, L., Koutsika, M., Papadopoulou, A., Xanthopoulos, V. 2005. Breeding for homozygotic superiority and stability in maize without loosing combining ability. Asian J. Plant Sci. 4:499-506.

Ipsilandis, C.G., Tokatlidis, I.S., Vafias, B., Stefanis, D. 2006. Criteria for developing second-cycle hybrid in maize. Asian J. Plant Sci. 5:680-685.

Kearsey, M.J., Pooni, H.S. 1992. The potential of inbred lines in the presence of heterosis. In: Dattee, Y., Dumas, C., Gallais, A. (eds), Reproductive Biology and Plant Breeding. Springer-Verlag. London, UK. pp. 371-386.

Kyriakou, D.T., Fasoulas, A.C. 1985. Effects of competition and selection pressure on yield response to winter rye (Secale cereale L.). Euphytica 34:883-895.

Moll, R.H., Bari, A., Stuber, C.W. 1977. Frequency distribution of maize yield before and after reciprocal recurrent selection. Crop Sci. 17:794-796.

Romagosa, I., Fox, P.N. 1993. Genotype $\times$ environment interaction and adaptation. In: Hayward, M.D., Bosemark, N.O., Romagosa, I. (eds). Plant Breeding Principles and Prospects. Chapman \& Hall. New York, USA. pp. 373-390.

Troyer, A.F., Wellin, J.E. 2009. Heterosis decreasing in hybrids: yield test inbreds. Crop Sci. 49:1969-1976.

\section{Electronic Supplementary Material (ESM)}

Electronic Supplementary Material (ESM) associated with this article can be found at the website of CRC at http://www.akademiai.com/content/120427/

Electronic Supplementary Table S1. Basic statistics for all years of experimentation (2007-2011) in the two environments $\mathrm{A}$ and $\mathrm{B}$ of progressive generations under the field designs used: Means of individual plants $(\bar{x})$ in $\mathrm{g}$, Coefficient of variation $(\mathrm{CV}) \%$, curve skewness and kurtosis

Electronic Supplementary Figure S1. The honeycomb NR-0 arrangement, with selection rings and plant yielding index as selection formula (where $x$ is the yield per plant, $\overline{x_{r}}$ is the mean plant yield of the surrounding plants within the moving ring)

Electronic Supplementary Figure S2. The honeycomb R-7 arrangement, with seven entries, plant yielding index and stability index as selection formula (where $x$ is the yield per plant, $\bar{x}_{r}$ is the mean plant yield of the surrounding plants within the moving ring, $\bar{x}$ and $s$ are the entry (family) mean yield and standard deviation) 